\section{What is already known on this topic}

Neonatal administration of vitamin $\mathrm{K}$ by the intramuscular route is effective in the prevention of haemorrhagic disease in newborn babies but has been suggested as a possible risk factor for leukaemia in children

A written record confirming that vitamin $\mathrm{K}$ has (or has not) been given is often not found, and some research groups have attempted to impute a child's vitamin K status from hospital policy

Nothing is known about how midwives interpret and implement vitamin K policies

\section{What this study adds}

Earlier hospital policies were open to individual interpretation and they were not always followed

There is considerable variation in current vitamin $\mathrm{K}$ policies and midwifery practice in the United Kingdom and no clear consensus on which babies should receive vitamin $\mathrm{K}$ intramuscularly

We thank the midwives for enthusiastically sharing their knowledge and experience and Peter Hope and Pat Townshend for comments on an earlier draft of the paper.

Contributors: PA initiated the study, was involved in all its aspects, and is the guarantor; ER contributed to study design, interpretation of data, and writing of the paper; NTF and MJR contributed to many discussions on vitamin $\mathrm{K}$ and to writing the paper.

Funding: Data collection was funded by a nursing research fellowship awarded to PA by the Smith and Nephew Foundation. Other aspects of the study were funded by the Leukaemia Research Fund.

Competing interests: None declared.

1 Golding J, Greenwood R, Birmingham K, Mott M. Childhood cancer, intramuscular vitamin $\mathrm{K}$, and pethidine given during labour. $B M J$ 1992;305:341-6.
2 Ekelund H, Finnstrom O, Gunnarskog J, Kallen B, Larsson Y. Administration of vitamin $\mathrm{K}$ to newborn infants and childhood cancer BMJ 1993;307:89-91.

3 Klebanoff MA, Read JS, Mills JL, Shiono PH. The risk of childhood cancer after neonatal exposure to vitamin K. N Engl J Med 1993;329:905-8.

4 Olsen JH, Hetz H, Blinkenberg K, Verder H. Vitamin K regimens and incidence of childhood cancer in Denmark. BMJ 1994:308:895-6.

5 Von Kries R, Göbel U, Hachmeister A, Kaletsch U, Michaelis J. Vitamin K and childhood cancer: a population based case-control study in Lower Saxony, Germany. BMJ 1996;313:199-203.

6 Ansell P, Bull D, Roman E. Childhood leukaemia and intramuscular vitamin K: findings from a case-control study. BMJ 1996;313:204-5.

7 McKinney PA, Juszczak E, Findlay E, Smith K. Case-control study of childhood leukaemia and cancer in Scotland: findings for neonatal intramuscular vitamin K. BMJ 1998; 316:173-7.

8 Passmore SJ, Draper G, Brownhill P, Kroll M. Ecological studies of relation between hospital policies on neonatal vitamin $\mathrm{K}$ administration and subsequent occurrence of childhood cancer. BMJ 1998;316:184-9.

9 Passmore SJ, Draper G, Brownhill P, Kroll M. Case-control studies of relation between childhood cancer and neonatal vitamin $\mathrm{K}$ administration. BMJ 1998;316:178-84.

10 Parker L, Cole M, Craft AW, Hey EN. Neonatal vitamin K administration and childhood cancer in the north of England: retrospective case-control study. BMJ 1998;316:184-93.

11 Barton JS, McNinch AW, Tripp JH. Oral vitamin K prophylaxis and frequency of late vitamin K deficiency bleeding. Lancet 1994;343:1168.

12 National Childbirth Trust. Parents'rights denied over vitamin K. Report to the Department of Health. London: NCT, 1994.

13 Department of Health. Vitamin K for newborn babies. Letter from the chief medical and nursing officers of England to all doctors, regional directors of public health, district nursing officers, midwives and health visitors. London: Stationery Office, 1998. (PL/CNO/998/4.)

14 Royal College of Midwives. Position paper 13b: vitamin K. RCM Midwives Journal 1999;2(8):252-3.

15 Department of Health. NHS hospital and community health services non-medical workforce census England: 30 September 1998. Detailed results. Leeds: NHS Executive, 1999.

16 Scottish health statistics 2000. Edinburgh: ISD Scotland, 2000:table P3.8. on www.show.scotnhs.uk/isd/Scottish_Health_Statistics/SHS2000/home. htm (accessed 23 March 2001)

17 Health Statistics and Analysis Unit, National Assembly for Wales, personal communication, 2000.

18 Project Support Analysis Branch, Northern Ireland Assembly, personal communication, 2000.

19 Barton JH, Tripp JS, McNinch AW. Neonatal vitamin K prophylaxis in the British Isles: current practice and trends. BMJ 1995;310:632-3.

20 Handel J, Tripp JH. Vitamin K prophylaxis against haemorrhagic disease of the newborn in the United Kingdom. BMJ 1991;303:1109.

21 Asch DA, Jedrziewski MK, Christakis NA. Response rates to mail surveys published in medical journals. J Clin Epidemiol 1997;50:1129-36.

(Accepted 8 March 2001)
Department of Public Health, University of Glasgow, Glasgow

G12 8QQ Kate Macintyre research fellow

Clinical Research Initiative in Heart Failure, University of Glasgow, Glasgow G12 8QQ

Simon Stewart National Heart Foundation of Australia postdoctoral overseas research fellow

John McMurray professor

continued over

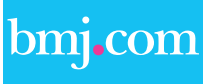

A table showing mortality per 1000 men and women appears on the BMJ's website

\title{
Relation between socioeconomic deprivation and death from a first myocardial infarction in Scotland: population based analysis
}

\author{
Kate Macintyre, Simon Stewart, James Chalmers, Jill Pell, Alan Finlayson, James Boyd,
} Adam Redpath, John McMurray, Simon Capewell

Health policy now explicitly addresses the increasing inequalities arising within many countries. ${ }^{1}$ Although it is generally accepted that socioeconomic factors influence the overall rates of coronary heart disease events, ${ }^{2}$ studies of case fatality after admission to hospital for acute myocardial infarction show only modest socioeconomic gradients. ${ }^{3}$ By focusing on those who survive to reach hospital, however, such studies may underestimate the true influence of socioeconomic deprivation. Reports suggest that around $70-80 \%$ of deaths within 30 days of a myocardial infarction occur before admission to hospital, and this proportion increases with age. ${ }^{4}$ We therefore examined the effect of socioeconomic deprivation not only on case fatality in patients admitted with myocardial infarction but also on the risk of death before admission.

\section{Participants, methods, and results}

Data were obtained from the Scottish Morbidity Record and General Register Office on all Scottish residents for whom a first myocardial infarction (code 410, international classification of diseases, 9th revision) was the principal cause of death or admission to hospital between 1986 and 1995. This database is linked to the Registrar General's data on death certificates, with an accuracy of $98 \%$. In a $1 \%$ sample of records checked in 1994, acute myocardial infarction as a principal diagnosis was 97\% accurate. First myocardial infarction was defined as no previous admission for this event since 1981. Postcodes were used to assign a Carstairs deprivation category to each individual, from 1 (least deprived) to 5 (most deprived). ${ }^{3}$ These categories are derived from 1991 
census data on four variables: overcrowding, the proportion of residents unemployed, those who do not have a car, and those who belong to a low occupational social class. Population rates were calculated by using the population structure by age, sex, and deprivation category.

Between 1986 and 1995 in Scotland, 44465 men (mean age (SD 11) 71.1) and 38710 women (mean age (SD 10) 77.7) died before being admitted to hospital after a first myocardial infarction. A further 68626 men and 49123 women were admitted to hospital, of whom $22.3 \%$ (95\% confidence interval 22.1\% to $22.6 \%$ ) died within 30 days. There was a socioeconomic gradient in all three parameters, which was greater in younger age groups (figure). The population based mortality in deprivation category 5 was more than twice that of category 1 in people aged under 65 (see table on website). Overall there were about 2000 excess deaths in the least affluent category compared with the most affluent (comparing the differential in observed over expected deaths in each deprivation category).

\section{Comment}

Socioeconomic deprivation has a profound effect on the risk of having a first myocardial infarction, the chance of reaching hospital alive, and the probability of surviving the first month. The effect of socioeconomic deprivation is greatest in women, with a twofold increase in death before reaching hospital in those under 65. The most deprived members of society under 65 have twice the risk of a first myocardial infarction and death before reaching hospital. Younger deprived men and women admitted to hospital are $20 \%$ more likely to die within the first month. One limitation of the study is that deprivation category is based on postcode rather than personal characteristics.

How socioeconomic deprivation increases these risks is probably multifaceted. The inverse care law is important but is only the last stage in a long sequence of events extending from the intrauterine period. ${ }^{5}$ To attain real equality requires strategies that target
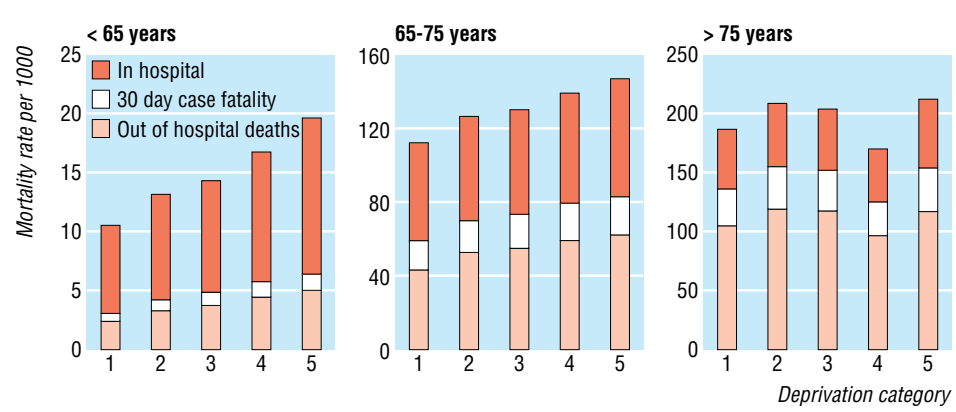

Rates per 1000 population of hospital admission for myocardial infarction, deaths before admission, and deaths within 30 days, by deprivation category 1986-95 (1=least deprived, $5=$ most deprived)

the wider determinants of health throughout an individual's life. As around $40 \%$ of people who experience a first myocardial infarction do not survive to reach hospital, the potential of acute treatment to reduce mortality is limited. Reducing mortality from heart disease requires a focus on primary prevention that explicitly addresses socioeconomic inequalities.

Contributors: KM designed the study, performed the analyses and interpretation, and wrote the first and final draft of the paper. SS, JMcM, SC, JP, and JC contributed to the design and interpretation and assisted with drafting the paper. $\mathrm{AF}, \mathrm{JB}$, and $\mathrm{AR}$ extracted the data and contributed to the interpretation and drafting of the paper. KM, JMcM, and SC will act as guarantors for the paper.

Funding: British Heart Foundation.

Competing interests: None declared.

1 National Heart Forum. Social inequalities in coronary heart disease: opportunities for action. London: Stationery Office, 1999.

2 Morrison C, Woodward M, Leslie W, Tunstall-Pedoe H. Effect of socioeconomic group on the incidence of management of and survival after myocardial infarction and coronary death; analysis of community coronary event register. BMJ 1997;314:541-6.

3 Capewell S, Kendrick S, Boyd J, Juszczak E, Clarke J. Measuring outcomes: one month survival after acute myocardial infarction in Scotland. Heart 1996;76:70-5.

4 Tunstall-Pedoe H, Morrison C, Woodward M. Sex differences in myocardial infarction and coronary deaths in the Scottish MONICA population of Glasgow 1985 to 1991. Circulation 1996;93:1981-92.

5 Barker DJP. Fetal origins of coronary heart disease. BMJ 1995;311:171-4.

(Accepted 27 October 2000)
Information and Statistics Division Edinburgh EH5 3SQ James Chalmers consultant Alan Finlayson senior health James Boyd principal statistician Adam Redpath principal statistician

Greater Glasgow

Health Board, Glasgow G3 8RH Jill Pell consultant

Department of Public Health, University of Liverpool, Liverpool L69 3GB Simon Capewell professor

Correspondence to: J McMurray J.McMurray@ bio.gla.ac.uk information scientist

\section{Email submissions from outside the United Kingdom}

We offer an email submission service for authors from outside the UK. The address is papers@bmj.com Ideally our email server would link seamlessly with our manuscript tracking system, but for now it does not, which is why we are offering the service only to authors outside the UK. Most post in the UK arrives the next day, so UK authors have the least to gain in speed of delivery from email delivery. As soon as our systems improve we will invite email submissions from everyone.

If you choose to send your submission by email please would you send the text and any tables and figures as attached files, together with a covering letter giving all your contact details (postal address, phone, fax, and email address). We can read files created with most word processing, graphics, and spreadsheet programs.

When your submission is received in our email box you will receive an automatic acknowledgment to show that it has arrived. If the submission is incomplete we will contact you and ask you to resend the missing information.

Once the submission is complete we will register it on our manuscript tracking system and you will receive a standard acknowledgment in the post.

Letters to the editor should continue to be sent direct to bmj.com as rapid responses or to letters@bmj.com 